\title{
OS DOUTORES DA ALEGRIA NA UNIDADE DE INTERNAÇÃO PEDIÁTRICA: EXPERIÊNCIAS DA EQUIPE DE ENFERMAGEM ${ }^{a}$
}

\author{
The Clown Doctors in a Pediatric Unit of Internment: \\ Experiences of the Nursing Staff \\ Los Doctores de la Alegría en una Unidad Pediátrica de Internación: \\ Experiencias del Equipo de Enfermería
}

\begin{abstract}
Resumo
0 estudo enfoca a experiência da equipe de enfermagem com a atuação dos Doutores da Alegria na unidade de internação pediátrica, tendo como objetivos: descrever os conhecimentos da equipe de enfermagem quanto à atuação dos Doutores da Alegria e analisar as experiências da equipe de enfermagem quanto a esta atuação. 0 estudo é de natureza qualitativa, e os sujeitos do estudo foram dez membros da equipe de enfermagem. Para a abordagem dos sujeitos, foi utilizada a entrevista não diretiva em grupo. Constata-se que a maioria das depoentes conhece a atuação dos Doutores da Alegria, sendo possível evidenciar reações e benefícios durante a hospitalização da criança, bem como a tríade de relações entre palhaços, mãe acompanhante e equipe de enfermagem. Conclui-se que os palhaços atuam como agentes facilitadores, atentando para o fato de que brincadeiras e brinquedos constituem recursos que podem/devem ser utilizados no contexto hospitalar, acarretando novos significados ao cuidar.
\end{abstract}

Palavras-chave: Equipe de Enfermagem. Criança hospitalizada. Jogos e brinquedos.

Abstract

The study was focused on the nursing staff experience with Clown Doctors intervention at one unit of pediatric internment. The objectives were to describe the nursing staff knowledge regarding the Clown Doctors' performance and to analyze the nursing staff experience with this group. A qualitative study was conducted with ten members of the nursing staff by applying non-directive interview in group. The results highlighted the recognition of the benefits of this intervention over the children illness recovery during their internment, as well as the triad of relations between clowns, accompanying mother and nursing staff. It is concluded that the clowns act as helpers agents, attempting against for the fact of that tricks and toys constitute resources, that may/might to be used in the hospital context, causing new meanings to the taking care of.

Keywords:

Nursing, Team. Child, Hospitalized. Play and Playthings.

\section{Resumen}

El estudio enfoca la experiencia del equipo de enfermería con los Doctores de la Alegría en una unidad pediátrica de internación, teniendo como objetivos: describir el conocimiento del equipo de enfermería cuanto a de la actuación de los Doctores de la Alegría y analizar las experiencias del equipo de enfermería cuanto a ellos. Estudio de naturaleza cualitativa, y los sujetos fueron diez miembros del equipo de enfermería Para el abordaje de los sujetos fue usado entrevista no directiva en grupo. Constatase que la mayoría de los deponentes conocían la actuación de los Doctores de la Alegría, siendo posible evidenciar reacciones y ventajas durante la hospitalización del niño, tan bien como la tríada de relaciones entre los payasos, la madre acompañando y el equipo de enfermería. Se concluye que los payasos actúan como agentes facilitadores, dando atención para el hecho de que trampeas y juguetes constituyen los recursos, de los cuales pueden/deben ser utilizados en el contexto hospitalario, causando nuevos significados al cuidado. 
Durante o curso de graduação em enfermagem, pude observar a atuação de palhaços junto a crianças hospitalizadas. A partir deste momento, surgiu o interesse por desenvolver um estudo voltado para o entendimento daquela situação, que provocou mudanças tão significativas em todos ali presentes e, em especial, na criança. Mediante essa vivência, decidi desenvolver a temática sobre os Doutores da Alegria na unidade de internação.

A justificativa do estudo baseia-se no fato de que os profissionais em geral são capacitados para lidar com padrões considerados de normalidade e anormalidade, mas tem dificuldades em promover a saúde das pessoas. Muitas vezes, não há estímulo para a busca do que há de mais saudável na criança, na sua essência, naturalmente lúdica.

A atividade lúdica está relacionada à motivação, que é intrínseca ao sujeito. Prado ${ }^{1: 159}$ destaca que:

Lúdico é uma categoria adjetivadora da atividade (que qualifica ludicamente), construída socialmente e de forma diferenciada em cada cultura. É um conjunto complexo de elementos especificamente humanos que cria espaços de jogo entre o "real" e o imaginário.

A doença impede a criança de desenvolver as atividades regulares de seu dia-a-dia e provoca, muitas vezes, sensações de dor, desconforto e mal-estar. A hospitalização leva a criança à necessidade de afastar-se do seu lar, sua escola, seus amigos, enfim, sua vida cotidiana, para ingressar em um ambiente completamente novo, com pessoas estranhas, imersas em uma rotina alheia ao seu modo de vida e um aparato terapêutico cuja finalidade é desconhecida para ela. ${ }^{2}$

Indubitavelmente as relações que ocorrem dentro do ambiente hospitalar irão influenciar diretamente o tratamento da criança. Durante o período de hospitalização, os membros da equipe de enfermagem são os indivíduos que estarão mais próximos da criança, com o objetivo de prestar os cuidados da melhor forma possível.

Desta forma, os profissionais deverão possuir uma boa compreensão do ser humano (criança), das suas necessidades, das suas capacidades e de seus desejos, tornando-se evidente o fato de que, quando a relação do profissional - cliente ocorre de maneira eficiente, a assistência prestada será a mais benéfica possível. Nesse caso, os "Doutores da Alegria" atuam tangenciando a assistência proporcionada pela equipe de enfermagem, uma vez que, se a essência saudável dessa criança está sendo estimulada, elas conseqüentemente estarão mais aptas e dispostas aos tratamentos propostos, o que também irá agir na melhora da sua condição de saúde, mesmo que esta não esteja especificamente centrada na cura de sua doença.

Assim, delimito como objeto de estudo a experiência da equipe de enfermagem com a atuação dos Doutores da Alegria na unidade de internação pediátrica. Os objetivos são: descrever os conhecimentos ${ }^{c}$ da equipe de enfermagem quanto à atuação dos Doutores da Alegria e analisar as experiências da equipe de enfermagem quanto à atuação dos Doutores da Alegria.

\section{ABORDAGEM METODOLÓGICA}

0 estudo é de natureza qualitativa. Este tipo de pesquisa preocupa-se com o universo de significados, motivos, aspirações, atitudes, entre outros, estabelecendo as ações e relações entre as pessoas. ${ }^{3}$

Os sujeitos do estudo foram 10 (dez) membros da equipe de enfermagem, que atuam em diferentes unidades de um hospital pediátrico do Município do Rio de Janeiro. A escolha dos membros foi aleatória, e a participação, voluntária, independente da categoria profissional, sendo uma enfermeira, cinco técnicos e quatro auxiliares de enfermagem. Para identificar os membros, foi utilizada a primeira letra de seus nomes.

Quanto ao número de membros da equipe de enfermagem, Lüdke \& André ${ }^{4: 441}$ ressaltam que na pesquisa qualitativa, quando há redundância de informação, os acréscimos são muito pequenos e há um sentido de integração nas informações, é um bom sinal para concluir o estudo".

Para proceder à coleta de dados, foi utilizada a técnica de entrevista não diretiva em grupo, que possibilita a obtenção de informaç̃̃es a partir do discurso livre dos entrevistados. Chizzotti i:92 ressalta que: 0 informante é competente para exprimir-se com clareza sobre questões da sua experiência e comunicar representações e análises... revelando tanto a singularidade quanto a historicidade dos atos, concepções e idéias...

Os temas que subsidiaram a entrevista não diretiva em grupo foram: conhecimento sobre atuação dos Doutores da Alegria e experiência profissional com os Doutores da Alegria.

Para a realização das entrevistas foi formado um grupo composto de quatro membros e dois grupos de três membros. A entrevista durou, em média, quarenta minutos.

A coleta de dados foi realizada após a aprovação e liberação pelo Comitê de Ética em Pesquisa da instituição, cenário do estudo. Para a obtenção dos dados foi utilizado como recurso um gravador, o que proporcionou 0 armazenamento dos depoimentos em fitas magnéticas. Mediante a aceitação dos membros da equipe de enfermagem, foi apresentado o Termo de Consentimento Livre e Esclarecido conforme a Resolução nº 196/96.

Após a transcrição, na íntegra, dos depoimentos, iniciou-se a análise temática. Inicialmente procedeu a leitura flutuante dos relatos, destacando os temas relevantes ao foco do estudo. Em seguida, os temas foram agrupados visando à estruturação dos tópicos do capítulo da análise.

\section{DOUTORES DA ALEGRIA: BREVE HISTÓRICO ${ }^{d}$}

Em 1986, Michael Christensen, um palhaço americano, diretor do Big Apple Circus de Nova York, iniciou o treinamento de um grupo de artistas, que passariam então a visitar crianças hospitalizadas. Ao realizar uma apresentação com o seu circo, em um determinado hospital de Nova York, Michael Christensen solicitou uma visita às crianças que estavam internadas e impossibilitadas de participar da apresentação. Assim, agindo de forma alegre, improvisada e despretensiosa, surge o grupo denominado Clown Care Unit. 
Em 1988, Wellington Nogueira, brasileiro, fundador e diretor artístico dos Doutores da Alegria, começa a integrar o grupo americano. Em setembro de 1991, iniciou-se a implementação de um projeto similar no Brasil, no Hospital e Maternidade Nossa Senhora de Lourdes (atual Hospital da Criança), em São Paulo, enquanto outros projetos que galgavam os mesmos objetivos começaram a ser implementados na França e Alemanha.

Os Doutores da Alegria fazem parte de uma organização da sociedade civil, sem fins lucrativos, mantida por patrocinadores e sócios mantenedores, que realiza cerca de 50 mil visitas por ano a crianças hospitalizadas no Estado de São Paulo, Rio de Janeiro e Recife. Tal iniciativa possui como objetivo principal proporcionar alegria às crianças hospitalizadas, bem como suas famílias e profissionais de saúde. 0 Centro de Estudos Doutores da Alegria surge devido à necessidade de ampliar os conhecimentos que cercam tal projeto, sistematizando suas ações nos hospitais e relacionando-as ao desenvolvimento da saúde, agregando artistas e profissionais com o mesmo propósito. Também visa propiciar aperfeiçoamento para os artistas que compõem o grupo, além de disponibilizar bibliografias para alunos e demais representantes de outras entidades.

A equipe de artistas que compõe o grupo é formada por profissionais especializados na arte do palhaço (áreas de teatro (lown), artes circenses e musicais. Os novos integrantes recebem treinamentos que objetivam a ambientação com a instituição que será visitada e demais procedimentos hospitalares, bem como são fornecidos regularmente cursos de aprimoramento técnico e artístico.

Os profissionais visitam cada unidade de internação duas vezes por semana, por aproximadamente seis horas diárias. Em duplas, percorrem cada leito (inclusive em unidades de terapia intensiva e ambulatórios), buscando, por cerca de seis meses, comparecer ao mesmo hospital, visando à criação de vínculos entre os diferentes profissionais que integram a equipe de saúde e familiares, vínculos estes que serão benéficos para criança. Como método de aproximação, possuem como princípio básico a aceitação da criança e, por meio de improvisação e caracterização (roupas, objetos, maquiagem), iniciam seu trabalho artístico.

Para difundir o trabalho desenvolvido pelo grupo, palestras são ministradas em congressos, hospitais e eventos, aliando informação e entretenimento em prol da apresentação dos valores e filosofia do grupo. Nessas ocasiões, eles procuram demonstrar como ocorrem as relações entre palhaços e ambiente hospitalar, bem como o poder humanizador de tais relações, e divulgar a importância da alegria no que concerne à superação de obstáculos, propiciando o surgimento de criatividade e transformações.

\section{AS BRINCADEIRAS E O LÚDICO: POSSIBILIDADES NO CONTEXTO HOSPITALAR}

Atualmente, muitos estudos são dedicados à compreensão do lúdico e das brincadeiras, como fatores fundamentais ao desenvolvimento humano. 0 ato de brincar torna-se objeto de inúmeros estudos que comprovam sua importância. Brincar é tão importante para a criança quanto provê-la de boa alimentação, sono tranqüilo, ambiente adequado de moradia, segurança, carinho e respeito. ${ }^{6}$ Assim, as brincadeiras passam a ser vistas não apenas como algo que proporcionam lazer e divertimento, mas como algo imprescindível na infância.

Toda criança possui uma cultura lúdica, e, desta forma, o brincar pode proporcionar uma nova realidade, própria e singular, possibilitando à criança a oportunidade de vir a expressar seus sentimentos, costumes, experiências, medos e preocupações. Segundo Cibreiros ${ }^{2: 4}$, O brincar é uma ocorrência natural, na qual a criança aprende sobre sie acerca do mundo em que vive, através dos brinquedos e das brincadeiras, sendo, também, essencial para o desenvolvimento físico, motor, cognitivo, emocional e social. A autora ainda ressalta que o brincar deve ser compreendido como uma necessidade vital da criança, que é capaz de contribuir para o seu desenvolvimento global.

Considerando que a atividade de brincar é de suma importância no período da infância, o parágrafo IV do artigo 16 do Estatuto da Criança e do Adolescente (ECA) garante o direito da criança à liberdade, sendo um de seus aspectos: Brincar, praticar esportes e divertir-se.?

A aplicação de recursos lúdicos no âmbito hospitalar transforma-se em um potencializador no processo de adaptação da criança, diante de transformações que ocorrerão a partir do momento em que ela é internada. É possível pensar ou questionar sobre a possibilidade de o brincar se constituir em uma estratégia adequada para o enfrentamento da hospitalização. Neste contexto, o ato de brincar consegue suprir as necessidades cognitivas e emocionais da criança.

\section{ATUAÇÃO DOS DOUTORES DA ALEGRIA: UMA ATIVIDADE LÚDICA}

Esse item apresenta a experiência da equipe de enfermagem com os Doutores da Alegria na unidade de internação pediátrica, analisando o conhecimento da referida equipe; a atuação dos Doutores da Alegria; as reações e benefícios para a criança hospitalizada; a influência na assistência de enfermagem; e a relação entre palhaços, equipe e acompanhante.

\section{CONHECIMENTOS DA EQUIPE DE ENFERMAGEM}

A maioria das depoentes desse estudo conhece a atuação dos Doutores da Alegria nas Unidades de Internação, sendo tal fato evidenciado nas falas:

Eu trabalhei quatro anos durante o dia, e eles vinham sempre pela manhã... Sei que não são médicos, mas palhaços, que chegam, brincam com as crianças... (A Auxiliar de enfermagem)

Eles são palhaços, têm aquela coisa de fazer a criança rir, se divertir e tudo o mais... A questão da brincadeira mesmo. ( $R$ - Técnica de Enfermagem)

Eles comparecem caracterizados, com nariz de palhaço, peruca, vários brinquedos e acessórios que ajudam nas brincadeiras. (T - Técnica de Enfermagem) 
Os Doutores da Alegria são profissionais especializados nas áreas de teatro clown e técnicas circenses, recebendo treinamento especifico para desempenhar seus trabalhos nas Unidades de Internação. A atuação almeja efeitos específicos dentro do contexto hospitalar, sendo um deles a colaboração com o tratamento proposto.

Em Ribeiro \& Sigaud ${ }^{8}$ temos que as atividades lúdicas são muito úteis quando é necessário que as crianças interajam com situações adversas. Tais atividades proporcionam o alívio de sensações desagradáveis como tensão, ansiedade, raiva e medo.

Chiattone $^{9}$ complementa essa idéia afirmando que, no âmbito da situação hospitalar, tem-se o brinquedo como principal recurso para a preparação de crianças para as diversas situações que podem ocorrer.

\section{O COTIDIANO DOS DOUTORES DA ALEGRIA: INFORMAÇÕES SOBRE A CRIANÇA}

As entrevistadas relatam a atuação dos Doutores da Alegria desde o primeiro momento das visitas nas unidades. A esse respeito, cabe ressaltar alguns depoimentos:

É sempre a mesma coisa: eles vão a cada leito, brincam, sem distinguir qual é a criança... Por exemplo, mesmo que exista uma criança com problemas neurológicos, que aparentemente não esteja entendendo nada, eles tratam como se ela estivesse entendendo tudo, brincam ali com a criança, como fazem com todas as outras, não diferenciam de acordo com a patologia... É como se todos estivessem entendendo tudo e brincando do mesmo jeito. (A - Técnica de Enfermagem)

...Perguntam a patologia da criança, se a criança pode ser manuseada, como é que pode ser, se pode sair do leito, se é acamada... Aqui é um setor específico, com muitas crianças de ortopedia, e eles sempre perguntam. (T - Técnica de Enfermagem)

Eles chegam, se apresentam com os nomes que eles inventam, os nomes profissionais... Então perguntam se existe alguma criança em isolamento de contato, se irá fazer algum procedimento, se tem qualquer tipo problema... Na nossa enfermaria eles aparecem duas vezes por semana, e sei que eles aparecem em todas as enfermarias... (C - Técnica de Enfermagem)

A primeira coisa que fazem é: entram aqui no posto, perguntam se tem algum isolamento, se tem alguma coisa que eles não podem tocar ou não podem aproximar dessa criança, lavam as mãos, brincam com a gente e vão para dentro da enfermaria... mas, antes de tudo, eles sempre entram no posto, e assim começam a brincadeira, daqui mesmo eles já saem brincando. (A - Auxiliar de Enfermagem)

Constata-se que não ocorre uma relação mais estreita entre os Doutores da Alegria e a equipe de enfermagem.

As providências tomadas pelos palhaços foram um fator verificado nos depoimentos. Ainda que eles visitem todos os leitos, têm a preocupação com a especificidade do caso de cada criança, respeitando também sua individualidade.

0 brinquedo e as brincadeiras devem ser direcionados à faixa etária específica da criança, ou mesmo à sua condição patológica. Para Leifer ${ }^{10}$, os brinquedos escolhidos e brincadeiras executadas devem ter como base a idade e o nível de atividade permitido, bem como os interesses da criança.

\section{AS CRIANÇAS: REAÇÕES E BENEFÍCIOS}

As depoentes descrevem as reações das crianças durante a atuação dos Doutores da Alegria:

Eu sei que, sempre que eles nos visitam, as crianças adoram, principalmente quem tem pouquinho mais de "raciocínio"... Porque aqui fica difícil, é complicado... A maioria das crianças é totalmente inerte, entubada... Eles visitam todas as crianças, mesmo aquelas que estão sedadas... E de uma maneira ou de outra, todas as crianças reagem bem às brincadeiras que eles fazem... Eles fazem um trabalho bem bonito com as crianças. (Z - Auxiliar de Enfermagem)

Eles transmitem muita alegria para as crianças, as crianças que já os conhecem já ficam aguardando aquela hora para poderem brincar, para participar... Até mesmo nos finais de semana eles ficam perguntando: Os Doutores não vêm? 0 palhaço não veio? As crianças ficam perguntando por eles, sinal de que eles fazem falta para elas. (T - Técnica de Enfermagem)

Eles interagem bastante com as crianças: ficam bastante alegres, mais ativas (E- Enfermeira)

Nesses depoimentos são identificadas as expectativas que as crianças possuem quanto ao retorno dos palhaços às enfermarias, fato que também pode ser avaliado como uma atitude positiva no processo de hospitalização. Para Masetti ${ }^{11}$ as crianças estariam formulando um objetivo, e pacientes que mantêm um objetivo de vida apresentam índices melhores quanto à sua recuperação.

Uma depoente ressalta a atuação dos Doutores da Alegria voltada para atender as necessidades psicossociais da criança:

Havia uma menina internada aqui, com problemas sérios no coração, a pressão ficava alterando... E ela quis muito um brinquedo que eles estavam usando, um instrumento que fazia um barulho, não sei qual o nome... Bastou ela querer, que eles deixaram... E era algo que eles iriam usar com as outras crianças também! Eu achei muito legal essa atitude deles... E quando cheguei perto dela, ela estava dormindo na cama abraçada com o tal brinquedinho. (M - Auxiliar de Enfermagem)

Constata-se que, apesar de implícito, a ação do palhaço possui um fundamento. 0 ato de deixar o brinquedo com a criança irá fazer com que ela se recorde da interação que teve com os palhaços, da experiência vivenciada por ela, mesmo quando estes estão ausentes, e isso irá auxiliar a criança a enfrentar a realidade durante a sua internação.

As depoentes mencionam a participação das crianças junto com os Doutores da Alegria, conforme é evidenciado: 
Algumas crianças já são antigas aqui, então quando eles chegam, as crianças os ajudam, querem fazer as coisas, querem participar junto com eles... Elas acabam melhorando. (J - Auxiliar de Enfermagem)

Eu acho importante porque as crianças ficam muito empolgadas; as maiores, então, querem andar com eles o tempo todo, correm atrás, ficam muito animadas... Eu acho muito interessante. 0 momento deles aqui dentro do hospital é especial de qualquer forma! (M - Auxiliar de Enfermagem)

Além da interação existente entre o palhaço e a criança durante as visitas, os encontros proporcionam a interação entre as próprias crianças, fato que continua sendo observado mesmo após a saída dos palhaços nessas unidades:

As crianças interagem bem, elas brincam muito umas com as outras... (T - Técnica de Enfermagem)

As crianças brincam muito junto a eles e também brincam juntas... Há um intercâmbio entre elas. (N Técnica de Enfermagem)

Mediante essa situação, foi constatado que os palhaços também proporcionam a socialização e interação entre as crianças, o que permite a criação de nova rede social, agindo também como circunstância facilitadora para saída do isolamento social, que, por vezes, a internação acaba provocando nessas crianças. Tal fato também pode ser associado à condição de recuperação.

\section{ASSISTÊNCIA DE ENFERMAGEM: INFLUÊNCIA DOS DOUTORES DA ALEGRIA}

No que concerne à assistência de enfermagem, a atuação dos Doutores da Alegria nas unidades também proporciona um melhor atendimento. As falas das depoentes permitem essa afirmativa:

No geral, elas dão boas risadas e se descontraem bastante... Assim, é muito mais fácil chegar perto depois que eles vão embora... Elas ficam mais relaxadas com a gente. ( $\mathrm{C}$ - Técnica de Enfermagem)

Outro aspecto identificado foi que a quebra da rotina hospitalar em nenhum momento interfere na assistência executada pela equipe de enfermagem, como é pontuado nas falas:

Eles ficam bastante tempo brincando aqui com as crianças, mas não atrapalham não, o nosso trabalho não, pelo contrário! (J - Auxiliar de Enfermagem)

Eles cantam, tocam músicas... tocam umas musiquinhas bem lentinhas no ouvido da criança, com um instrumento feito de coco... até que elas fiquem bem calmas. ( $\mathrm{R}$ - Técnica de Enfermagem)

Os profissionais de enfermagem que atuam nos hospitais possuem um imenso contato com doenças, sofrimento, angústias e morte, além da sobrecarga de trabalho e responsabilidades. A partir dos relatos, evidencia-se que a possibilidade de ver a atuação dos palhaços nas enfermarias proporciona alegria e descontração aos membros da equipe de enfermagem, o que, conseqüentemente, será observado na prestação dos cuidados às crianças, como mudanças nas condutas adotadas e inúmeros outros benefícios. Masetti ${ }^{12: 23}$ ressalta que:

Apesar de o trabalho dos Doutores da Alegria ser dirigido para a criança, tem efeitos extensivos a pais, profissionais de saúde e funcionários do hospital... Esses resultados se traduzem pela diminuição do estresse no trabalho, melhora da autopercepção profissional e da imagem do hospital, bem como melhora da comunicação entre os membros da equipe e destes com os familiares e pacientes.

A humanização no cenário hospitalar pode ser mais bem planejada se oferecida num ambiente favorável, estruturando programas dirigidos especialmente à criança, através da inclusão do brinquedo. Pode-se com isso acelerar a recuperação da criança, contribuindo para a diminuição dos dias de permanência no hospital e, conseqüentemente, do custo da hospitalização. ${ }^{13}$

Atualmente, muitas propostas vêm sendo elaboradas para tornar a enfermagem pediátrica menos normativa e menos distante do ser criança, contudo Mitre ${ }^{14}$ afirma que, para os profissionais de saúde saberem fazer do brincar um ato significativo voltado à necessidade da criança, devem rever toda uma realidade hospitalar, o que se constitui num verdadeiro desafio. Ainda, a autora destaca que, nesta perspectiva, seria deslocar-se da doença para a saúde.

A atuação dos palhaços também possibilita, por parte dos profissionais, a observação de que os fatores decorrentes da patologia apresentada pela criança, como por exemplo, apatia, prostração, depressão e resistências, possam estar ligados às condições do ambiente hospitalar e às relações vividas dentro do próprio hospital.

\section{TRÍADE DE RELAÇÕES: PALHAÇO - EQUIPE - MÃE ACOMPANHANTE}

Foi possível constatar que é estabelecida uma relação entre os palhaços e a equipe de enfermagem, que propicia motivação e possibilidade de também participar das brincadeiras. Os depoimentos a seguir ilustram o exposto:

Eles até me chamam por um apelido carinhoso! Eles também brincam muito com a gente. ( $Z$ - Auxiliar de Enfermagem)

Divertem as crianças e a gente também... 0 trabalho deles para as crianças é ótimo e para a gente também, que gargalhamos com eles. (G - Técnica de Enfermagem)

0 ato de brincar também possibilita os profissionais vivenciarem uma relação diferente com as crianças, não lidando apenas com as incapacidades e limitações. Assim, o lúdico mais uma vez privilegia o que é saudável e prazeroso, e este instrumento de trabalho se vincula ao conceito que esses profissionais possuem acerca do tratamento e cura ${ }^{15}$.

Motta \& Enumo ${ }^{16}$ apontam que o brincar constitui-se em uma das possíveis estratégias que são utilizadas tanto pela criança quanto pelos profissionais do hospital para lidarem com 
as adversidades da hospitalização. A esse respeito, cabe ressaltar alguns depoimentos:

Daqui eles já saem brincando, começa com a gente! E depois melhoram o nosso trabalho também... (M - Auxiliar de Enfermagem)

Também acabam alegrando, descontraindo o pessoal aqui do setor, porque acaba que nós também entramos no meio da brincadeira... (C - Técnica de Enfermagem)

As mães acompanhantes, parte integrante e de suma importância nesse cotidiano da criança que se encontra hospitalizada, também são beneficiadas pela presença dos Doutores da Alegria:

Eu acho muito bom, porque eles trazem alegria tanto para as crianças quanto para mães, que ficam aqui dentro fechadas... Para nós é diferente, viemos aqui, trabalhamos 12 horas e vamos embora... Elas não, são todos os dias, 24 horas aqui dentro. ( $\mathrm{J}$ - Auxiliar de Enfermagem)

A presença da mãe acompanhando a criança constitui uma das formas mais eficazes para minimizar traumas emocionais e psicológicos provocados pela hospitalização. Para Souza \& Oliveira ${ }^{17}$, esta presença traz benefícios para a mãe e a criança, representando segurança e conforto. Ainda, Andrade $18: 28$ ressalta que: Torna-se imprescindível, no momento da internação, a presença de um elemento da família, em especial a mãe, acompanhando a criança.

A melhora nessa interação mãe/criança é constatada no relato a seguir:

As mães também são muito unidas, muito comunicativas e participam das brincadeiras junto com a criança... (N - Técnica de Enfermagem)

Pode-se constatar que, além da melhora da condição da mãe, a interação equipe/mãe também é beneficiada, o que conseqüentemente proporciona melhora da qualidade na interação equipe/criança, conforme depoimento:

As mães também melhoram... Trazem alegria até para determinadas mães, que estão mal humoradas... Elas também ficam melhores, até quando falam com a gente. (M - Auxiliar de Enfermagem)

No que tange à atuação da enfermagem durante todo esse processo, temos Huerta ${ }^{19: 157}$ corroborando a idéia de que: $\dot{E}$ fundamental a interação dos profissionais de saúde com as mães, no sentido de lhes proporcionar um relacionamento significativo, permeado de apoio psicológico.

\section{Referências}

1.Prado MMR. Descobrindo o lúdico: a vivencia lúdica infantil na sociedade moderna. Rev Terap Ocup USP 1991; 2(4): 159-66.

2. Cibreiros SA, Oliveira ICS. A comunicação do escolar por intermédio dos brinquedos: um enfoque para à assistência de enfermagem nas Unidades de Cirurgia Pediátrica. Rio de Janeiro(RJ): 2000.
Em pesquisas realizadas pelo Centro de Estudos dos Doutores da Alegria, alguns pais relatam que o sorriso das crianças funciona como um indicador importante da recuperação física de seus filhos. Os pais também se tornam mais ativos no tratamento dos filhos, lidam melhor com a hospitalização das crianças e percebem uma alteração positiva na imagem da internação. Para estes, a mudança na condição emocional da criança, a partir da atuação dos palhaços, é de importância fundamental na sua própria condição emocional. ${ }^{11}$

\section{CONSIDERAÇÕES FINAIS}

Tendo em vista a temática desenvolvida neste estudo, foi possível entender não apenas como a atuação dos Doutores da Alegria influencia de forma positiva a condição de saúde das crianças, mas também como se dá a interação entre os Doutores da Alegria, os membros da equipe de enfermagem e as mães acompanhantes.

Com os depoimentos, constata-se que a atuação dos Doutores da Alegria acarreta inúmeros benefícios às crianças hospitalizadas, como mudanças de comportamento diante da hospitalização, interação e socialização com outras crianças e melhoria da capacidade de enfrentamento durante o período de internação.

Evidenciou-se que há influência também na assistência de enfermagem, devida à interação entre Doutores da Alegria e equipe de enfermagem e, principalmente, pela condição que a criança apresenta após a atuação dos palhaços nas unidades de internação.

Os Doutores da Alegria interagem com as mães acompanhantes, proporcionando a elas momentos de lazer e descontração, fato que pode ser considerado de grande valia, já que, durante a internação de seus filhos, estas estão sujeitas a inúmeros momentos de dor e sofrimento.

Uma série de conseqüências pode ser evidenciada nesse estudo, contudo, cabe ressaltar que iniciativas como as dos Doutores da Alegria, que possibilitam a presença do palhaço e das brincadeiras no ambiente hospitalar, acarretam novos significados ao cuidar.

Este estudo não pretende esgotar a temática abordada, mas contribuir para uma reflexão sobre a utilização do lúdico, das brincadeiras e da presença dos palhaços nas unidades de internação pediátrica, sendo outras pesquisas necessárias, com abordagens específicas, que visem sempre à melhoria da qualidade e humanização da assistência de enfermagem à criança.

3. Minayo MCS. 0 desafio do conhecimento: pesquisa qualitativa em saúde. $3^{\text {a }}$ ed. São Paulo(SP): Hucitec; 1994.

4. Ludke M, André MED. Pesquisa em educação: abordagens qualitativas. São Paulo (SP): EPU; 1986.

5.Chizzotti A. Pesquisa em ciências humanas e sociais. São Paulo (SP): Cortez; 1991. 
6. Alves AMA, Silva SR. Brincadeiras na infância: crescimento e saúde. In: Figueiredo NMA, organizador. Práticas de enfermagem: ensinando a cuidar da criança. São Paulo (SP): Difusão Paulista de Enfermagem; 2003.

7. Ministério da Saúde (BR). Estatuto da criança e do adolescente. Brasília (DF); 1991.

8. Ribeiro MO, Sigaud CHS. Relacionamento e comunicação com a criança e sua família. In: Sigaud CHS, Verissimo MR, organizadores. Enfermagem pediátrica: 0 cuidado de enfermagem à criança e ao adolescente. São Paulo (SP): EPU; 1996.

9. Chiatonne HSB. A significação da psicologia no contexto hospitalar. São Paulo(SP): Pioneira; 2000.

10. Leifer G. Ludoterapia e intervenção de enfermagem para bebes e crianças hospitalizadas. In: Princípios e técnicas em enfermagem pediátrica. $4^{\mathrm{a}}$ ed. São Paulo(SP): Santos 1999.

11. Masetti M. Soluções de palhaços: transformações na realidade hospitalar. São Paulo (SP): Palas Athena; 1998.

12. Masetti M. Boas misturas: a ética da alegria no contexto hospitalar. São Paulo (SP): Palas Athena; 2003.

13. Soares MRZ. Hospitalização infantil: análise do comportamento da criança e do papel da psico saúde. São Paulo (SP): Pediátrica Moderna; 2001.

14. Mitre RMA. Brincando para viver: um estudo sobre a relação entre a criança gravemente adoecida e hospitalizada e o brincar. [dissertação de mestrado]. Rio de Janeiro(RJ): Instituto Fernandes Figueira/FIOCRUZ; 2000.

15. Mitre RMA, Gomes R. A promoção do brincar no contexto da hospitalização infantil como ação de saúde. Cienc Saude Colet 2004; 9(1): 147-54.

16. MottaAB, Enumo SRF. Brincar no hospital: estratégia de enfrentamento da hospitalização infantil. Psicol Estud 2004 jan/ abr; 9 (1): $19-28$.
17. Souza CCF, Oliveria ICS. A participação da mãe nos cuidados ao seu filho hospitalizado: uma perspectiva da equipe de enfermagem. Esc Anna Nery Rev Enferm 2003 dez; 7 (3): 379-87.

18. Andrade VRO. Interação criança/mãe/equipe de enfermagem em processo de hospitalização. Rev Enferm UERJ 1993 ago; 1 (2): 28-29.

19. Huerta EPN. A experiência de acompanhar um filho hospitalizado: sentimentos, necessidades e expectativas manifestados por mães acompanhantes. Rev Esc Enferm USP 1985; 19(2): 153-71.

\section{Notas}

a Este estudo corresponde ao requisito da disciplina "Estudos de Problemas Emergentes da Prática Profissional" do Curso de Graduação em Enfermagem e Obstetrícia da Escola de Enfermagem Anna Nery da Universidade Federal do Rio de Janeiro (EEAN/ UFRJ). 0 estudo obteve o $2^{\circ}$ lugar do Prêmio Dulce Neves da Rocha, oferecido pelo Núcleo de Pesquisa de Enfermagem em Saúde da Criança do Departamento de Enfermagem MaternoInfantil da EEAN/UFRJ, em 2005.

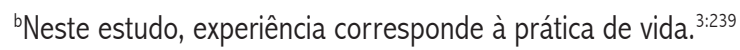

'Conhecimento adquirido por prática, estudo, observação. 4:346

${ }^{d} 0$ texto acerca dos Doutores da Alegria foi obtido no site http:// www.doutoresdaalegria.com.br; Acessado em setembro de 2004.

eA palavra "palhaço" foi utilizada neste estudo, pois algumas depoentes assim denominavam os Doutores da Alegria. 